\title{
Protective effects of Curcuma longa against cerulein-induced acute pancreatitis and pancreatitis-associated lung injury
}

\author{
SANG-WAN SEO ${ }^{1 *}$, GI-SANG BAE ${ }^{2 *}$, SUNG GYU KIM $^{1}$, SEUNG-WON YUN ${ }^{1}$, MIN-SUN KIM ${ }^{2}$, \\ KI-JUNG YUN ${ }^{3}$, RAE-KIL PARK ${ }^{4}$, HO-JOON SONG ${ }^{2}$ and SUNG-JOO PARK ${ }^{2}$ \\ ${ }^{1}$ ChungBuk Oriental Medicine Center, Jecheon, ChungBuk 390-250; ${ }^{2}$ Department of Herbology, \\ School of Oriental Medicine; ${ }^{3}$ Department of Pathology; ${ }^{4}$ Vestibulocochlear Research Center and Department of \\ Microbiology, College of Medicine, Wonkwang University, Iksan, Jeonbuk 570-749, Republic of Korea
}

Received July 14, 2010; Accepted September 7, 2010

DOI: $10.3892 / \mathrm{ijmm} .2010 .548$

\begin{abstract}
Curcuma longa (CL) has been reported to possess a variety of pharmacological activities. However, the effects of CL on acute pancreatitis (AP) have not yet been determined. To this end, we examined the effects of CL on ceruleininduced AP. Cell viability and cytokine productions were measured in pancreatic acini. Mice were divided into 3 groups: i) Normal group, ii) normal saline-treated group, iii) group treated with CL at a dose of $0.05,0.1,0.5$ and $1 \mathrm{~g} / \mathrm{kg}$. CL was administered orally to mice for 7 days. The mice were intraperitoneally injected with the stable cholecystokinin analogue, cerulein $(50 \mu \mathrm{g} / \mathrm{kg})$, every hour for a total of $6 \mathrm{~h}$. The mice were sacrificed $6 \mathrm{~h}$ after the completion of the cerulein injections. Blood samples were obtained to determine serum amylase, lipase and cytokine levels. The pancreas was rapidly removed for morphological examination, measurement of tissue myeloperoxidase activity, as well as the level of cytokines and heme oxygenase-1 (HO-1). The CL treatment reduced cerulein-induced cell death and cytokine production in pancreatic acini. The administration of CL significantly ameliorated the severity of pancreatitis and pancreatitisassociated lung injury, as was shown by the reduction in pancreatic edema, neutrophil infiltration, vacuolization, necrosis, serum amylase, lipase and cytokine levels, and mRNA expression of multiple inflammatory mediators such as interleukin (IL)-1ß and -6 and tumor necrosis factor (TNF)- $\alpha$. In order to identify the regulatory mechanism of $\mathrm{CL}$ on cerulein-induced pancreatitis, we examined the level of HO-1 in the pancreas. We found that the administration
\end{abstract}

Correspondence to: Professor Sung-Joo Park, Department of Herbology, School of Oriental Medicine, Wonkwang University, Iksan, Jeonbuk 570-749, Republic of Korea

E-mail: parksj08@wku.ac.kr

${ }^{*}$ Contributed equally

Key words: Curcuma longa, acute pancreatitis, cerulein, acinar cell, heme oxygenase-1 of CL induced HO-1. Our results suggest that CL plays a protective role in the development of AP and pancreatitisassociated lung injury.

\section{Introduction}

The incidence of acute pancreatitis (AP) is increasing worldwide and $20 \%$ of cases are associated with substantial morbidity and mortality $(1,2)$. AP is, therefore, one of the more prominent emerging diseases. AP, which is characterized by interstitial edema, vacuolization, inflammation and acinar cell necrosis, is commonly caused by excessive ethanol consumption, biliary tract disease, certain medications, and invasive procedures of the biliary and pancreatic ducts (3-6). The pathophysiology of AP is poorly understood, and its clinical course is unpredictable (7).

Pancreatic acinar cells synthesize and release cytokines and chemokines, resulting in the recruitment of inflammatory cells such as neutrophils and macrophages. This leads to further acinar cell injury, resulting in the elevation of various pro-inflammatory mediators such as interleukin (IL)- $1 \beta$ and IL-6, and tumor necrosis factor (TNF)- $\alpha(8,9)$. The release of inflammatory mediators such as TNF- $\alpha$ and IL- $1 \beta$ during AP propagates a complex cascade of events between tissue vasculature and inflammatory cells. These inflammatory cells and mediators, besides modulating pancreatic acinar cell injury, play a role in the systemic manifestations by blocking the cytokine cascade in its early stage, and ameliorating the disease and its systemic complications (10).

The rhizomes of Curcuma longa L. (CL), commonly known as turmeric, are widely used in food and medicine. Turmeric extracts have been shown to possess powerful antioxidant, anti-inflammatory, lipid-reducing, chemo-preventive, immunomodulatory, and sedative properties $(11,12)$. In the present study, we determined the preventive effects of CL on cerulein-induced AP. In order to gain better insight into the mechanism of action of the observed anti-inflammatory effects of CL, we investigated the effects of CL in 2 ways: The first one involved in vitro experiments using pancreatic acinar cells, and the other one involved in vivo experiments including pancreatic histology, pancreatic weight/body weight $(\mathrm{PW} / \mathrm{BW})$ ratio, serum amylase, lipase and cytokine 
levels, and mRNA levels of pro-inflammatory mediators, such as TNF- $\alpha$, IL-1ß and -6 , as well as lung histology and myeloperoxidase (MPO) activity.

\section{Materials and methods}

Chemicals and reagents. Avidin-peroxidase, 2'-azino-bis (3-ethylbenzithiazoline-6-sulfonic acid) tablets, cerulein, Tris- $\mathrm{HCl}, \mathrm{NaCl}$, Triton X-100, hexadecyltrimethylammonium bromide, curcumin and tetramethylbenzidine, were purchased from Sigma (St. Louis, MO, USA). Anti-mouse TNF- $\alpha$, IL-1ß and IL- 6 antibodies, recombinant TNF- $\alpha$, and IL-1ß and -6 , were purchased from R\&D Systems (Minneapolis, MN, USA). Anti-heme oxygenase-1 (HO-1) antibody was purchased from Santa Cruz Biotechnology, Inc. (Santa Cruz, CA, USA).

Preparation of $C L$. CL was purchased from a standard commercial source (Omni Herb, Seoul, Korea). The identity of the herb was confirmed at the Korean drug test laboratory. Voucher specimens were deposited at the College of Oriental Medicine Herbarium of Wonkwang University. CL was prepared by decocting the dried prescription of herbs $(100 \mathrm{~g})$ with boiling distilled water (1 l). The decoction time was $\sim 2 \mathrm{~h}$. The water extract was frozen at $-80^{\circ} \mathrm{C}$, then freeze-dried in order to be powdered $(20.8 \mathrm{~g})$. The yield of extract was $20.8 \%$. The powder was extracted with distilled water and filtered. The filtrates were stored at $4^{\circ} \mathrm{C}$ until use.

Animal models. All experiments were performed according to the protocols approved by the Animal Care Committee of the University. Female C57BL/6 mice (6-7 weeks old, weighing 18-20 g) were purchased from Orient Bio Co. (Sungnam, KyungKiDo, Republic of Korea). All animals were bred and housed in standard shoebox cages in a climate controlled environment with an ambient temperature of $23 \pm 2^{\circ} \mathrm{C}$ and a 12 -h light-dark cycle for 7 days. The animals were fed standard laboratory chow, given water and were randomly assigned to the control or experimental groups. The mice were fasted for $18 \mathrm{~h}$ before the induction of AP. Six mice were included in each experimental group.

Experimental design. AP was induced by a supra-maximal concentration of cerulein $(50 \mu \mathrm{g} / \mathrm{kg})$, a stable cholecystokinin (CCK) analogue, by administering it intraperitoneally every hour for a total of $6 \mathrm{~h}$, as described previously (13). The mice were fed orally with CL $(0.05,0.1,0.5$ and $1 \mathrm{~g} / \mathrm{kg}, \mathrm{n}=6$ each) or normal saline (control group, $\mathrm{n}=6$ ) for 7 days, followed by the intraperitoneal injection of cerulein $(50 \mu \mathrm{g} / \mathrm{kg})$ or saline every hour for a total of $6 \mathrm{~h}$. The mice were sacrificed $6 \mathrm{~h}$ after the completion of the cerulein injections. Blood samples were obtained in order to determine serum amylase, lipase and cytokine levels. The pancreas was rapidly removed for morphological examination and scoring. A portion of the pancreas was stored at $-70^{\circ} \mathrm{C}$ and prepared for the measurement of tissue MPO activity, an indicator of neutrophil sequestration, and for reverse-transcriptase (RT) polymerase chain reaction (PCR) and real-time RT-PCR measurements.

Histological analyses. From each treatment group of 6 mice, the entire pancreas was examined and semi-quantified based on the degree of necrosis, vacuolization, inflammation and edema. Using a previously described method (13), entire sections (a minimum of 100 fields) of pancreas were examined from each sample and scored on a scale of 0-3 ( 0 being normal and 3 being severe), based on the number of necrotic acinar cells, and the presence of vacuolization, interstitial edema and inflammation. The characteristics included were: The presence of acinar-cell ghosts, vacuolization and swelling of the acinar cells, and/or the destruction of the histoarchitecture of whole or parts of the acini.

Enzyme-linked immunosorbent assay (ELISA). ELISA for TNF- $\alpha$, IL-1ß and -6 (R\&D Systems) was carried out in duplicate in 96-well plates (Nunc, Denmark), coated with each of the following: Aliquots $(100 \mu 1)$ of anti-mouse TNF- $\alpha$, IL-1ß and -6 monoclonal antibodies at $1.0 \mu \mathrm{g} / \mathrm{ml}$ in PBS at $\mathrm{pH} 7.4$, and they were then incubated overnight at $4^{\circ} \mathrm{C}$. The plates were washed in PBS containing $0.05 \%$ Tween-20 (Sigma) and blocked with PBS containing 1\% BSA, 5\% sucrose and $0.05 \% \mathrm{NaN}_{3}$ for $1 \mathrm{~h}$. After additional washes, the standards, acinar cell supernant and blood samples, were added and incubated at $37^{\circ} \mathrm{C}$ for $2 \mathrm{~h}$. After incubation for $2 \mathrm{~h}$ at $37^{\circ} \mathrm{C}$, the wells were washed, and $0.2 \mu \mathrm{g} / \mathrm{ml}$ of biotinylated anti-mouse TNF- $\alpha$, IL- $1 \beta$ and -6 were added, and they were again incubated at $37^{\circ} \mathrm{C}$ for $2 \mathrm{~h}$. After the wells were washed, avidin-peroxidase was added and the plates were incubated for $20 \mathrm{~min}$ at $37^{\circ} \mathrm{C}$. The wells were again washed and ABTS substrate was added. Color development was measured at $405 \mathrm{~nm}$ using an automated microplate ELISA reader. A standard curve was run on each assay plate using recombinant TNF- $\alpha$, IL- $1 \beta$ and -6 in serial dilutions.

Measurement of serum amylase and lipase levels. Arterial blood samples for the determination of serum amylase and lipase levels were obtained $6 \mathrm{~h}$ after the last induction of pancreatitis. The mice were anesthetized with an intraperitoneal injection of ketamine $(80 \mathrm{mg} / \mathrm{kg})$ and xylazine $(4 \mathrm{mg} / \mathrm{kg})$. After anesthetization, blood samples were withdrawn from the heart. The serum amylase level was measured using Adiva 1650 (Bayer, USA). The serum lipase level was measured using a Cobas Mira (Roche, USA).

Real-time RT-PCR. mRNA transcripts were analyzed by realtime RT-PCR in mouse pancreatic acini and tissues. Total RNA was isolated from the mouse pancreas and pancreatic acini using TRIzol and was subjected to reverse transcription using SuperScript RT (Invitrogen). TaqMan quantitative RTPCR with the LightCycler System was carried out according to the instructions of the manufacturer (Roche). For each sample, triplicate test reactions and a control reaction lacking reverse transcriptase were analyzed for the expression of the gene of interest, and the results were normalized to those of the 'housekeeping' HPRT mRNA. Arbitrary expression units were calculated by the division of the expression of the gene of interest by ribosomal protein HPRT mRNA expression. The forward, reverse and probe oligonucleotide primers for multiplex real-time TaqMan PCR were as follows: For mouse TNF- $\alpha$ (forward, 5'-TCT CTT CAA GGG ACA AGG CTG-3'; reverse, 5'-ATA GCA AAT CGG CTG ACG GT-3'; probe, 5'-CCC GAC TAC GTG CTC CTC ACC CA-3'), for mouse 
IL-1ß (forward, 5'-TTG ACG GAC CCC AAA AGA T-3'; reverse, 5'-GAA GCT GGA TGC TCT CAT CTG-3'; universal probe, M15131.1-Roche Applied Science), for mouse IL-6 (forward, 5'-TTC ATT CTC TTT GCT CTT GAA TTA GA-3'; reverse, 5'-GTC TGA CCT TTA GCT TCA AAT CCT-3'; universal probe, M20572.1-Roche Applied Science), for mouse HPRT (forward, 5'-GAC CGG TCC CGT CAT GC-3'; reverse, 5'-CAT AAC CTG GTT CAT CAT CGC TAA-3'; probe, 5'-ACC CGC AGT CCC AGC GTC GT-3'). For mouse HO-1, we purchased a custom primer from Applied Biosystems.

MPO estimation. Neutrophil sequestration in the pancreas was quantified by measuring the tissue MPO activity (13). Tissue samples were thawed, homogenized in $20 \mathrm{mmol} / \mathrm{l}$ phosphate buffer ( $\mathrm{pH} 7.4)$, centrifuged $(10,000 \mathrm{x} \mathrm{g}, 10 \mathrm{~min}$, $4^{\circ} \mathrm{C}$ ), and the resulting pellet was resuspended in $50 \mathrm{mmol} / \mathrm{l}$ phosphate buffer ( $\mathrm{pH} 6.0$ ) containing $0.5 \%$ hexadecyltrimethylammonium bromide (Sigma). The suspension was subjected to 4 cycles of freezing and thawing and was further disrupted by sonication $(40 \mathrm{sec})$. The sample was then centrifuged $\left(10,000 \times \mathrm{g}, 5 \mathrm{~min}, 4^{\circ} \mathrm{C}\right)$, and the supernatant used for the MPO assay. The reaction mixture consisted of the supernatant, $1.6 \mathrm{mmol} / \mathrm{l}$ tetramethylbenzidine (Sigma), $80 \mathrm{mmol} / \mathrm{l}$ sodium phosphate buffer ( $\mathrm{pH} 5.4$ ), and $0.3 \mathrm{mmol} / 1$ hydrogen peroxide. The mixture was incubated at $37^{\circ} \mathrm{C}$ for $110 \mathrm{sec}$, the reaction was terminated with $2 \mathrm{~mol} / \mathrm{l}$ of $\mathrm{H}_{2} \mathrm{SO}_{4}$, and the absorbance was measured at $540 \mathrm{~nm}$. This absorbance was then corrected for the DNA content of the tissue sample (fold increase over control).

Preparation of pancreatic acinar cells. Pancreatic acini were obtained from the mouse pancreas by collagenase treatment as previously described (13). Briefly, the fresh pancreases were infused with buffer A (mM: $140 \mathrm{NaCl}, 4.7 \mathrm{KCl}, 1.13$ $\mathrm{MgCl}_{2}, 1 \mathrm{CaCl}_{2}, 10$ glucose and 10 HEPES, pH 7.3) containing $200 \mathrm{IU} / \mathrm{ml}$ type IV collagenase and $0.5 \mathrm{mg} / \mathrm{ml}$ soybean trypsin inhibitor. The tissue was minced and incubated in a shaking water bath for $10 \mathrm{~min}$ at $37^{\circ} \mathrm{C}$. In order to obtain dispersed acini, the digested tissue was passed through small pipette tips. The cells were then passed through a solution of $50 \mathrm{mg} / \mathrm{ml}$ bovine serum albumin and then washed twice with buffer A before further experiments.

MTT assay. Pancreatic acinar cells were seeded in a flatbottomed, 24-well plate at $2 \times 10^{5}$ cells/well in Waymouth medium plus $10 \%$ FBS. The cells were pre-treated with CL at the indicated doses, then incubated with cerulein for $6 \mathrm{~h}$. Before harvesting, $50 \mu 1$ of the vital dye MTT (SigmaAldrich) in PBS $(5 \mathrm{mg} / \mathrm{ml})$ were added to the cultures. The blue dye taken up by the cells after 30-min incubation was dissolved in DMSO (200 $\mu \mathrm{l} /$ well). Readouts were taken at a $540 \mathrm{~nm}$ wavelength using an automated micro-plate reader.

Western blot analysis. The pancreases were homogenized in RIPA buffer. Then the supernatants were extracted, and used as cell lysates. Whole cell lysates were made by boiling acinar cells in sample buffer $(62.5 \mathrm{mM}$ Tris- $\mathrm{HCl}, \mathrm{pH}$ 6.8, $2 \%$ sodium dodecyl sulfate (SDS), $20 \%$ glycerol and 10\% 2-mercaptoethanol). Proteins in the cell lysates were then separated by
$10 \%$ SDS-PAGE and transferred to a nitrocellulose membrane. The membrane was then blocked with 5\% skim milk in PBSTween-20 (PBST) for $2 \mathrm{~h}$ at room temperature and then incubated overnight with antibodies against HO-1. After washing 3 times in PBST, each blot was incubated with secondary antibody for $1 \mathrm{~h}$ and the antibody-specific proteins were visualized using an enhanced chemiluminesence detection system (Amersham, Piscataway, NJ) according to the manufacturer's instructions.

Statistical analysis. The results were expressed as the means $\pm \mathrm{SD}$. The significance of change was evaluated using the Student's t test. Differences between the experimental groups were evaluated by using the analysis of variance. Values of $\mathrm{P}<0.05$ were considered to be statistically significant.

\section{Results}

Effect of CL on cerulein-induced cytokine production in acinar cells. AP is characterized by pancreatic acinar cell death. Therefore, we examined the effects of CL on pancreatic acinar cell death. Pancreatic acinar cells, were pre-treated for $1 \mathrm{~h}$ with CL and then stimulated with cerulein for $6 \mathrm{~h}$. Cerulein induced pancreatic acinar cell death. However, CL significantly increased the viability of pancreatic acinar cells in a dose-dependent manner (Fig. 1A). The cytokine expression has been found to be up-regulated in ceruleinstimulated pancreatic acinar cells in the absence of inflammatory cells (5). Therefore, we investigated the effects of CL on the production of inflammatory mediators in isolated pancreatic acini. CL inhibited the cerulein-induced production of inflammatory mediators such as TNF- $\alpha$, IL- $1 \beta$ and -6 (Fig. 1B). In addition, RNA was extracted from isolated pancreatic acinar cells, and real time RT-PCR was performed. Similar to the in vitro results, CL inhibited the levels of TNF- $\alpha$, IL-1 $\beta$ and -6 mRNA expression (Fig. 1C).

Effect of CL on pancreatic histology during cerulein-induced $A P$. In normal mice, the histological features of the pancreas were typical of a normal architecture. Mice treated with intraperitoneal injections of cerulein developed acute necrotizing pancreatitis. Histological examination of the pancreas $(6 \mathrm{~h}$ after the final injection of cerulein) revealed tissue damage characterized by inflammatory cell infiltrate and acinar cell necrosis. The CL pre-treatment resulted in a significant reduction in pancreatic injury (Fig. 2A). Edema, inflammation, vacuolization and necrosis in the CL-pre-treated group, were significantly reduced compared to the normal saline-pretreated group, in a dose-dependent manner (Fig. 2B).

Effect of $C L$ on $P W / B W$ ratio, serum amylase and lipase activity in cerulein-induced AP. In order to assess the effect of $\mathrm{CL}$ on the $\mathrm{PW} / \mathrm{BW}$ ratio, the $\mathrm{PW}$ was divided by the $\mathrm{BW}$ of the mice. $\mathrm{CL}$ reduced the $\mathrm{PW} / \mathrm{BW}$ ratio, compared to the normal saline-treated group (Fig. 3A). Serum amylase and lipase levels are most commonly obtained as biochemical markers of pancreatic disease, particularly AP. Serum amylase activity has been used for many years for the evaluation of patients with acute abdominal pain and suspected pancreatic disorders (14). The elevation of serum pancreatic lipase levels 

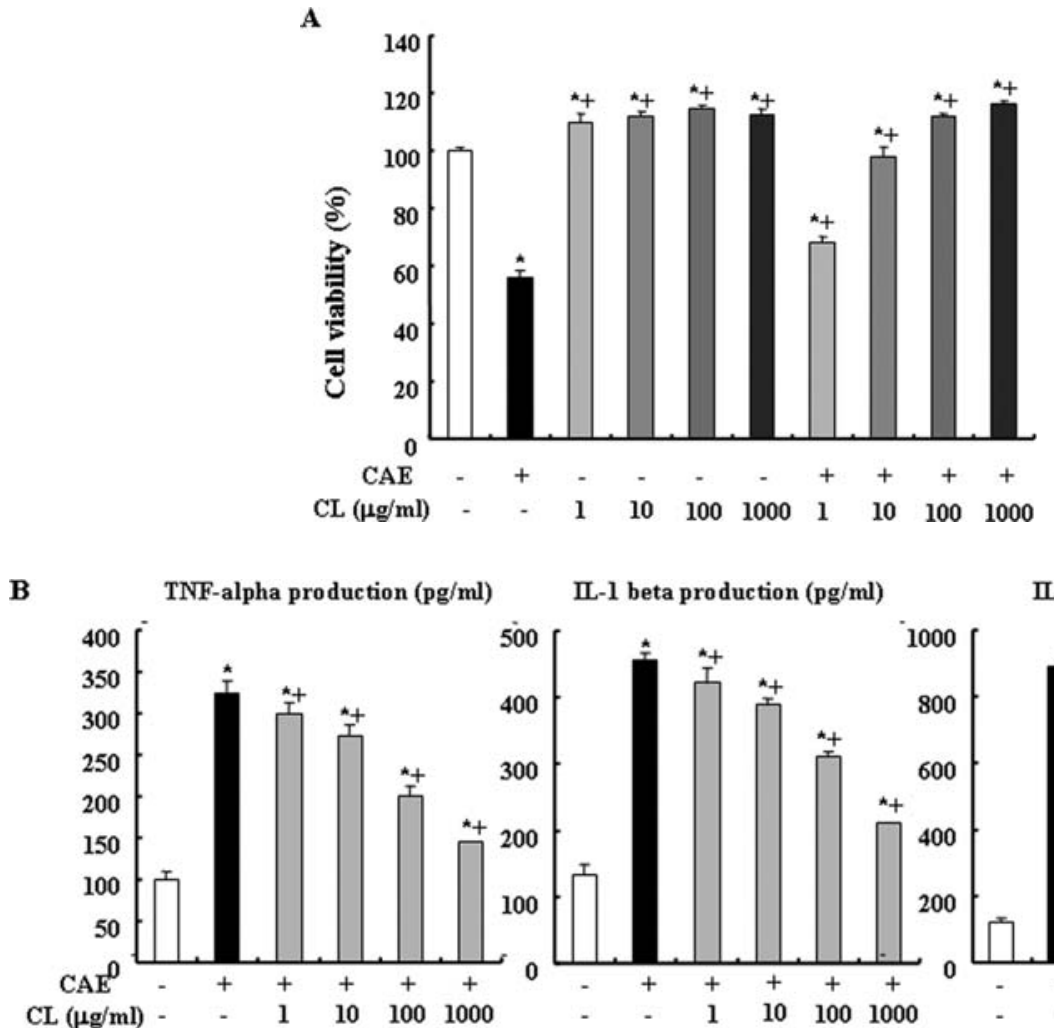

IL-1 beta production $(\mathrm{pg} / \mathrm{ml})$

IL-6 production $(\mathrm{pg} / \mathrm{ml})$

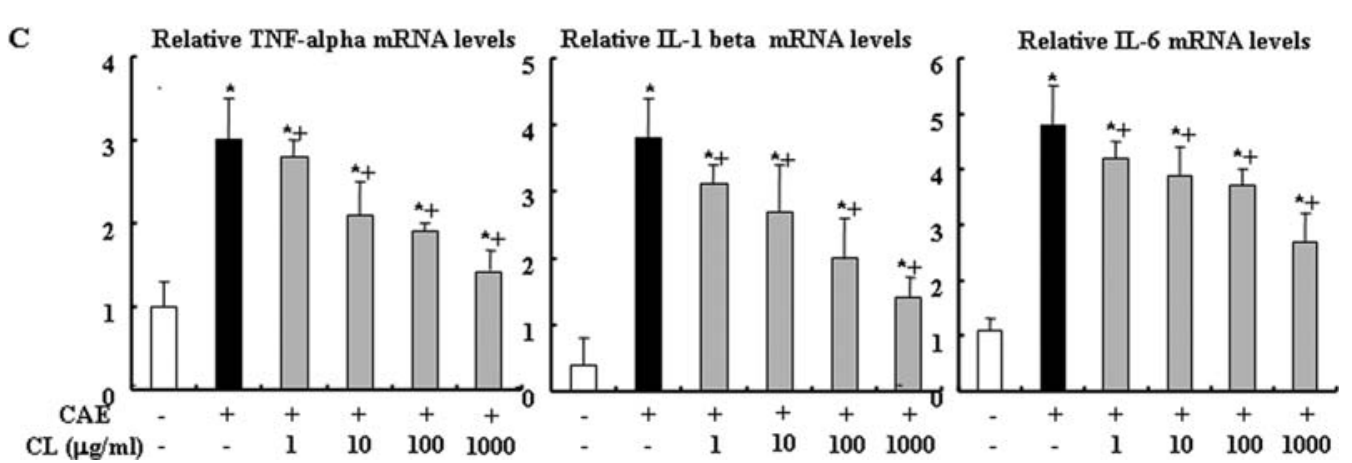

Figure 1. The protective effects of CL on cerulein-induced acinar cell damage. The cells were pre-treated with CL for $1 \mathrm{~h}$ at the indicated dose. (A) After 6-h cerulein (final concentration $1 \mathrm{nM}$ ) incubation, the cell viability was measured as indicated in the experimental protocol. (B) After 12-h cerulein (final concentration $1 \mathrm{nM}$ ) incubation, the cytokine levels were examined in isolated pancreatic acinar cells by ELISA. (C) The levels of mRNA were quantified by real-time RT-PCR for TNF- $\alpha, \mathrm{IL}-1 \beta$ and -6 . Results shown are the means $\pm \mathrm{SD} .{ }^{*} \mathrm{P}<0.05$ vs. saline treatment, ${ }^{+} \mathrm{P}<0.05$ vs. cerulein treatment alone.

is often considered to be the most sensitive and specific marker of AP (15). The serum amylase and lipase levels are commonly used as markers of AP (14-16). Therefore, we examined serum amylase and lipase activity during ceruleininduced AP. The administration of CL significantly reduced the serum amylase and lipase levels (Fig. 3B and C).

Effect of CL on TNF- $\alpha, I L-1 \beta$ and -6 in cerulein-induced AP. Several inflammatory mediators have been shown to increase in AP (16). Therefore, in order to examine the effect of CL on the occurrence of a systemic inflammatory response during cerulein-induced AP, the productions of TNF- $\alpha$, IL-1ß and -6 were measured in serum. The serum levels of proinflammatory cytokines, such as TNF- $\alpha$, IL-1ß and -6 , were increased during cerulein-induced AP. The increase of these inflammatory mediators in serum was significantly attenuated by the administration of CL (Fig. 4A). In addition to the measurement of inflammatory mediators in serum, we also determined the levels of TNF- $\alpha$, IL- $1 \beta$ and -6 mRNA in the pancreas during cerulein-induced AP. As shown in Fig. 4B, the administration of CL significantly reduced the pancreatic tissue mRNA expressions of inflammatory mediators such as TNF- $\alpha$, IL- $1 \beta$ and IL-6.

Effect of CL on lung histology during cerulein-induced AP. Lung injury commonly develops early in AP. AP-associated lung injury is characterized by edema and inflammation (16). In addition to the pancreas, we assessed the lungs after cerulein administration. Histological examination of lung sections ( $6 \mathrm{~h}$ after the final injection of cerulein) revealed tissue damage characterized by edema and inflammatory cell infiltrate. The CL pre-treatment resulted in a significant reduction in lung injury. The histological sections were scored for edema and inflammation. The lungs from the CL- 
A

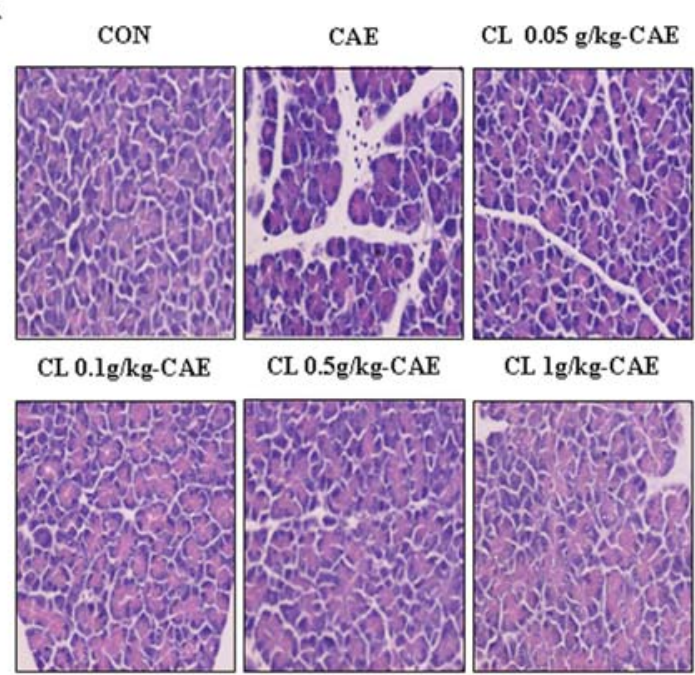

B

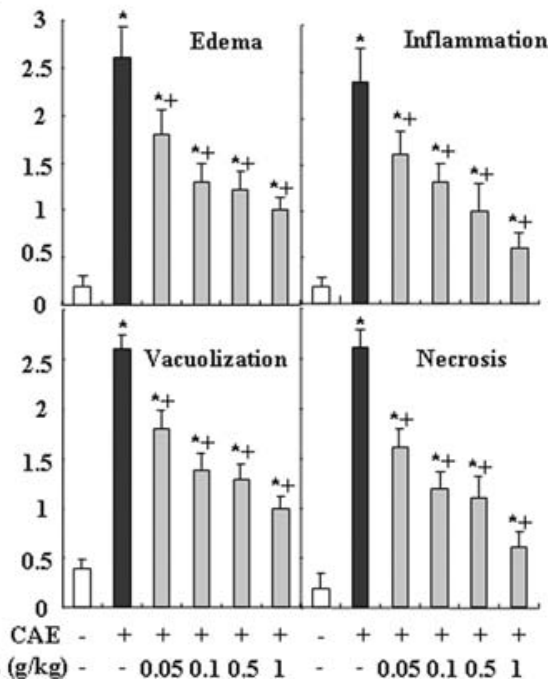

Figure 2. Effects of the CL on pancreatic inflammatory changes following pancreatitis. (A) Representative H\&E-stained sections of pancreas in control mice who were not given cerulein, in those given cerulein, and in those given CL at the indicated doses. (B) Histological sections of pancreas harvested $6 \mathrm{~h}$ after the final cerulein injection. The results were scored from 0 (normal) to 3 (severe) for edema, inflammation, vacuolization and necrosis. ${ }^{*} \mathrm{P}<0.05$ vs. saline treatment, ${ }^{+} \mathrm{P}<0.05$ vs. cerulein treatment alone. Shown are the results of 1 experiment in which 6 mice were tested per group. The results obtained were similar to those in 3 additional experiments. Original magnification, x200. CON, control mice; CAE, cerulein.

A

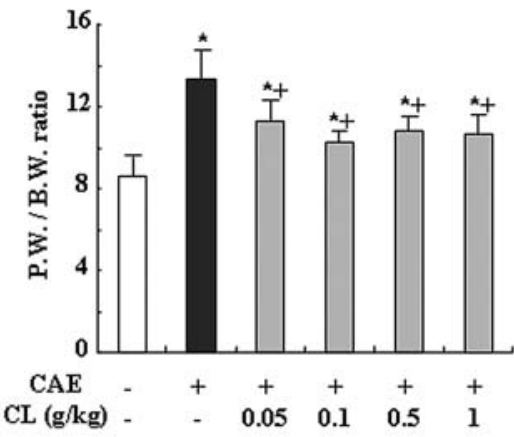

B

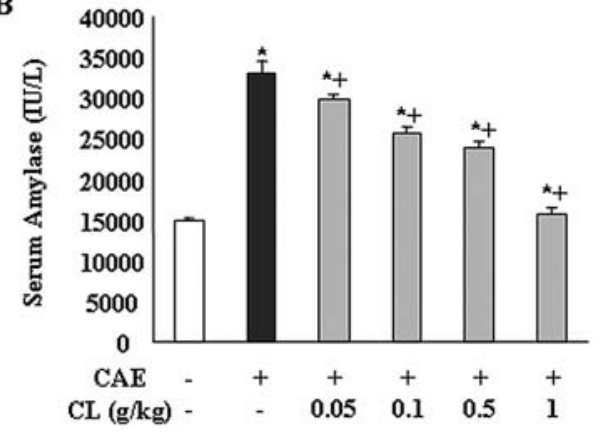

C

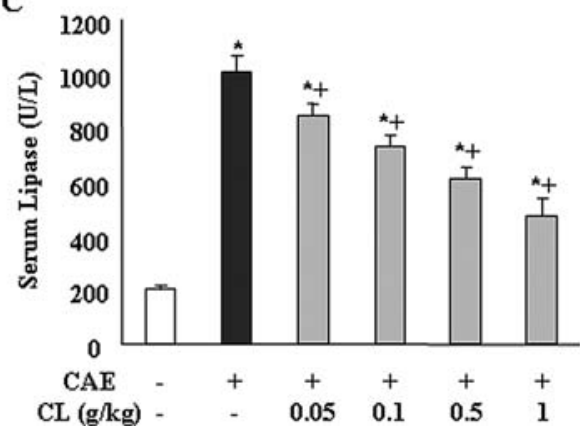

Figure 3. Effects of CL pre-treatment on the (A) PW/BW, (B) serum amylase activity, and (C) serum-lipase activity in cerulein-induced AP. The study groups were treated as indicated in the experimental protocol. The means $\pm \mathrm{SD}$ of 6 animals are shown. ${ }^{*} \mathrm{P}<0.05$ vs. saline treatment, ${ }^{+} \mathrm{P}<0.05$ vs. cerulein treatment alone. The results obtained were similar to those in 3 additional experiments.

pre-treated mice had significantly less edema and inflammation compared to those from the saline-injected control animals (Fig. 5A and B).

Effect of CL on MPO activity during cerulein-induced AP. As an additional quantitative assessment of the severity of the inflammatory response, we measured MPO activity, an indicator of neutrophil sequestration, in the pancreas and lung following the induction of AP in the CL-pre-treated mice and saline-injected control animals. MPO activity in the pancreas and lung in the CL-pre-treated mice was significantly lower compared to the saline-injected control animals (Fig. 6A and B).

Effect of CL on HO-1 induction during cerulein-induced AP. Curcumin is a polyphonic compound with immunomodulatory 
A

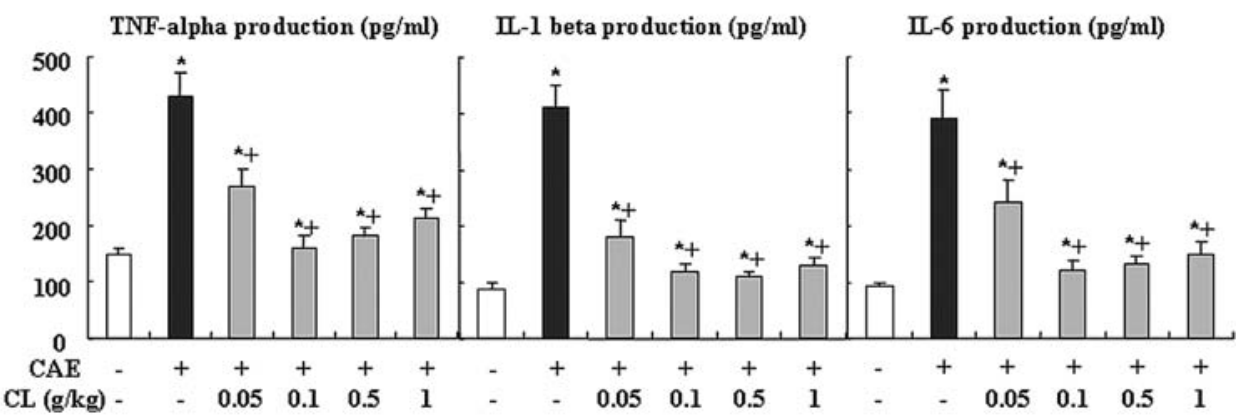

B

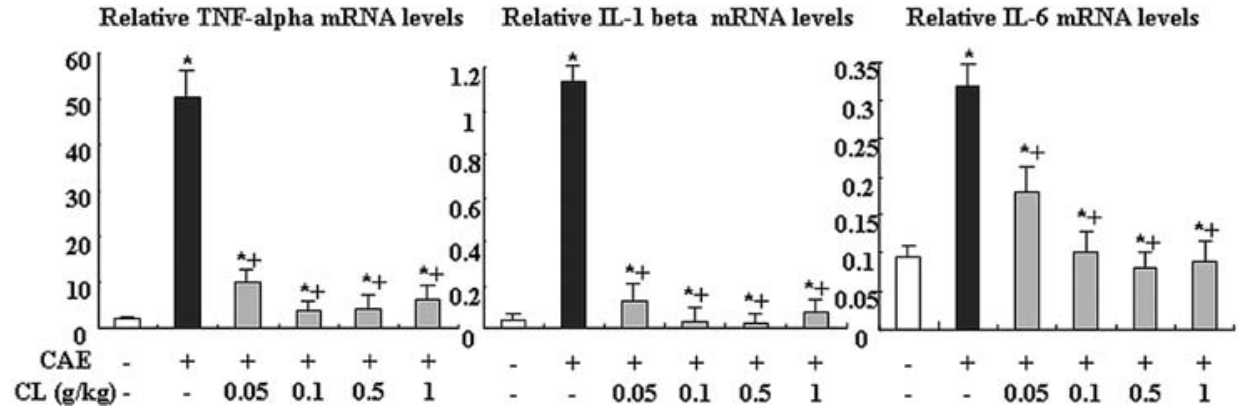

Figure 4. Effects of CL on (A) serum level and (B) mRNA levels of TNF- $\alpha$, IL-1ß and -6 secretion in cerulein-induced AP. Mice were treated as indicated in the experimental protocol. Levels of serum cytokine were measured by ELISA and pancreatic mRNA was quantified by real-time RT-PCR. The means \pm SD of 6 animals are shown. The study groups were treated as indicated in the experimental protocol. ${ }^{*} \mathrm{P}<0.05$ vs. saline treatment, ${ }^{+} \mathrm{P}<0.05$ vs. cerulein treatment alone. The results obtained were similar to those in 3 additional experiments.

A
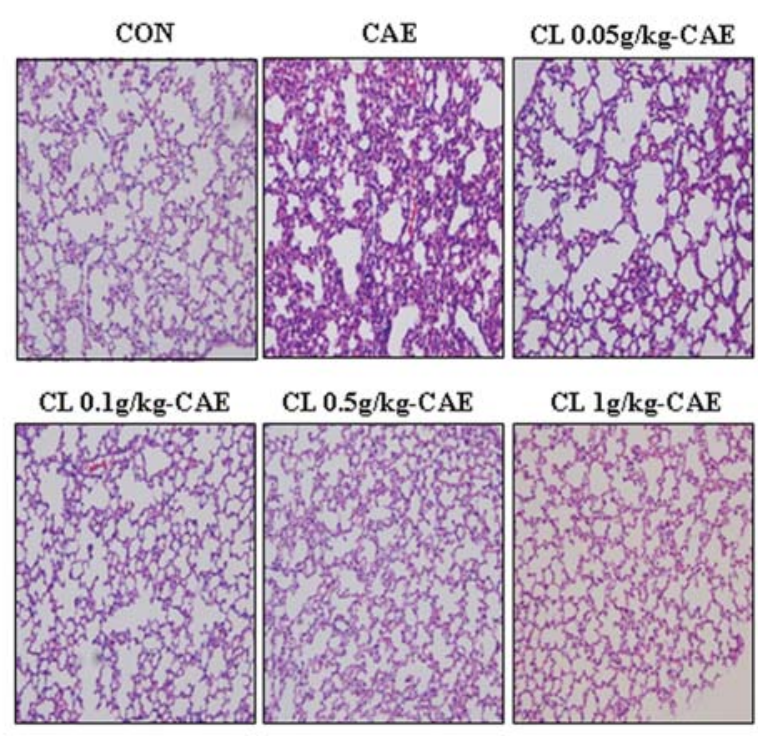

CL lg/kg-CAE

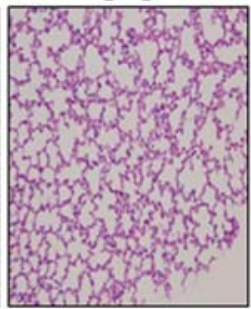

B
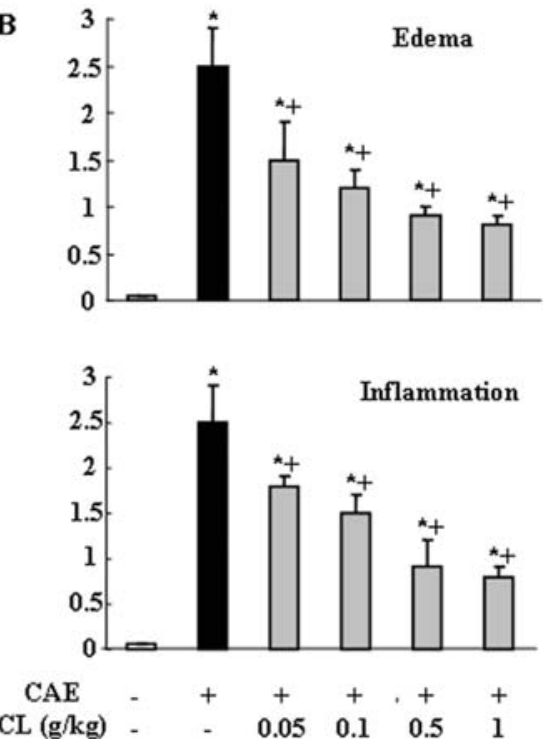

Figure 5. Effects of CL on AP-associated lung injury. (A) Representative H\&E-stained sections of the pancreas in control mice who were not given cerulein, in those given cerulein, and in those given CL at the indicated doses. (B) Histological sections of the lung harvested $6 \mathrm{~h}$ after the final cerulein injection. The results were scored from 0 (normal) to 3 (severe) for edema, inflammation, vacuolization, and necrosis. " $\mathrm{P}<0.05$ vs. saline treatment, ${ }^{+} \mathrm{P}<0.05$ vs. cerulein treatment alone. Shown is one experiment in which 6 mice were tested per group. The results obtained were similar to those in 3 additional experiments. Original magnification, x200. CON, control mice; CAE, cerulein.

properties derived from the rhizomes of the CL plant (17). Curcumin has been known to induce HO-1, which exhibits certain biological properties, including anti-inflammatory (18-21) and antioxidant (22) properties. Therefore, we examined the effect of $\mathrm{CL}$ on $\mathrm{HO}-1$ induction in comparison to curcumin during cerulein-induced AP. Mice treated with intraperitoneal injection of curcumin or CL for $6 \mathrm{~h}$. As shown in Fig. 7A and B, curcumin induced HO-1 expression dramatically in the pancreas. The HO-1 expression in the CLtreated group was lower compared to that in the curcumin- 
A. Pancreas MPO

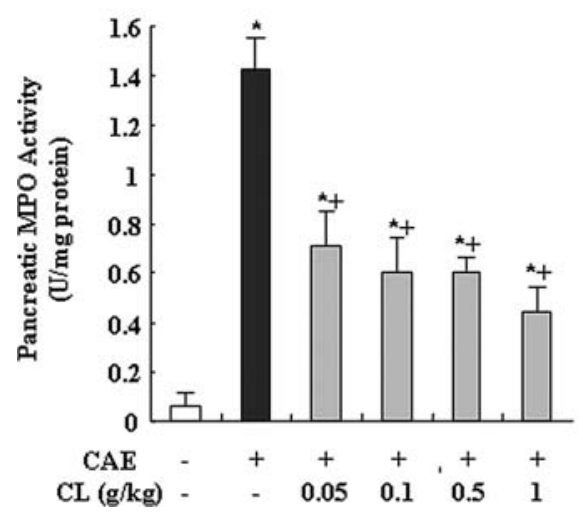

B. Lung MPO

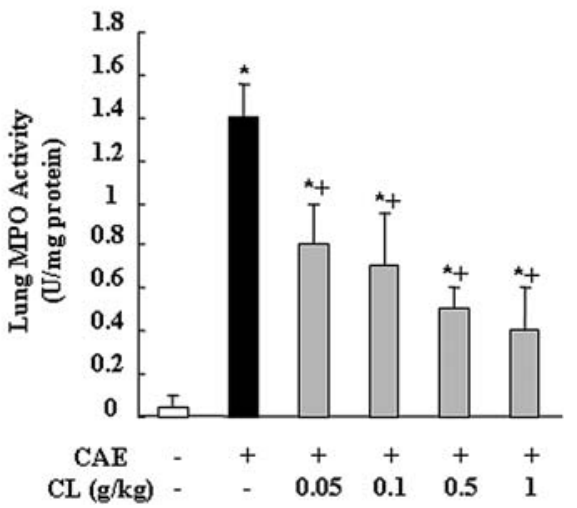

Figure 6. Effects of CL on the cerulein-induced MPO activity. The MPO activity was measured in the pancreas $6 \mathrm{~h}$ after completion of the cerulein injections and in the saline-injected control mice. The data are expressed as MPO activity (U/mg protein). ${ }^{*} \mathrm{P}<0.05$ vs. saline treatment, ${ }^{+} \mathrm{P}<0.05$ vs. cerulein treatment alone. The results obtained were similar to those in 3 additional experiments. CAE, cerulein.

$\mathbf{A}$

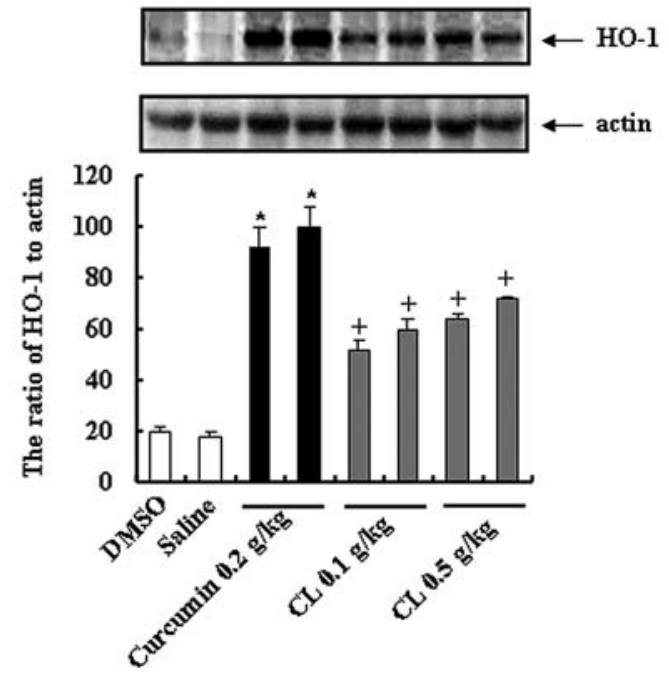

B

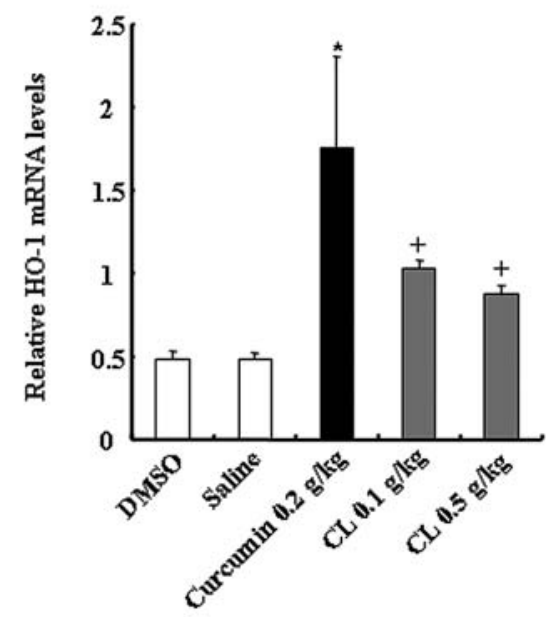

Figure 7. Effects of CL on HO-1 expression. DMSO, saline, curcumin or CL were injected, then 6 h later, the pancreas was harvested. Curcumin was injected as the reference compound. (A) The protein level of HO-1 was measured by Western blot analysis. (B) The mRNA expression of HO-1 was measured by realtime RT-PCR. The procedure is described in detail in Material and methods. The results obtained were similar to those in 3 additional experiments.

treated group. Nevertherless, HO-1 was induced by CL significantly, in comparison to the saline-injected control group.

\section{Discussion}

CL has long been used in traditional Asian medicine to treat gastrointestinal upset, arthritic pain, urinary tract infection, and liver ailments $(23,24)$. However, the precise pharmacological mechanism of CL is still unknown. The main component of CL, curcumin, has also been shown to possess anti-inflammatory, antioxidant and antimicrobial properties (25). The present study investigated whether CL inhibits cerulein-induced AP as well as cell death in isolated pancreatic acinar cells. We show that CL improves the severity of AP (Fig. 2) as well as the viability of pancreatic acinar cells (Fig. 1A).

The results of the present study indicate that cerulein caused significant morphological abnormalities in the pancreas, as was demonstrated by the appearance of vacuolization, inflammatory infiltration and changes in the histoarchitecture of the pancreatic acini. The pre-treatment with CL inhibited acinar cell death as well as the infiltration by inflammatory cells in cerulein-induced AP. In order to rule out interference by the binding of cerulein to $\mathrm{CCK}$ receptors on pancreatic acinar cells, we examined the effects of CL on pancreatic acinar cells. CL did not have any cytotoxic effect after $6 \mathrm{~h}$. However, CL inhibited cerulein-induced acinar cell death in a dose-dependent manner (Fig. 1A-C). These results suggest that CL improved the severity of pancreatitis through the inhibition of pancreatic acinar cell death.

Growing evidence suggests that the activation of proinflammatory cytokines, such as TNF- $\alpha$, IL-1ß and -6 , could play an important role in the development of AP $(26,27)$. TNF- $\alpha$ has been shown to be an important initiator of local and systemic damage occurring in AP and the blocking of the 
action of this cytokine has been shown to delay the onset of AP (9). Additionally, serum TNF- $\alpha$ levels have been found to be correlated with the severity of AP in humans (28). IL-1B has been shown to be a significant cytokine for the development of AP and the inhibition of its production has been shown to decrease the severity of AP $(29,30)$. It has been shown that IL-6 levels in severe pancreatitis were significantly elevated compared to mild pancreatitis. Therefore, IL-6 is a principal mediator of acute phase response and is released from activated mononuclear phagocytes $(31,32)$. Taken together, our results demonstrate that CL significantly reduces the production of inflammatory mediators such as TNF- $\alpha$, IL- $1 \beta$ and -6 during cerulein-induced AP and also inhibits the cerulein-induced production of pro-inflammatory cytokines (Fig. 4A and B).

The initial attack of AP is closely followed by a second stage consisting of the immigration of leukocytes into the pancreas as early as $3 \mathrm{~h}$ after the application of the first noxious stimulus (13). As the condition develops, leukocytes migrate into the pulmonary interstitium and increase endothelial permeability, resulting in tissue edema. Pulmonary injury is a potentially devastating complication in AP and, in its most severe form (i.e. adult respiratory distress syndrome), is associated with a mortality rate of $\sim 30 \%$ (13). In accordance with the reduction in MPO activity, the severity of lung injury was significantly reduced in the CL-treated mice (Fig. 5). Our results suggest that CL can improve the systemic inflammatory changes in the lung which are associated with pancreatitis.

HO-1, the inducible isoform of heme oxygenase that catabolizes heme into free iron, carbon monoxide and bilirubin/biliverdin, has been shown to possess antiinflammatory properties (33). The anti-inflammatory action of HO-1 is mediated by the reduction in leukocyte adhesion, thus diminishing the production of pro-inflammatory cytokines (34). Hemin, the agent for HO-1 induction, offers protection against injury in experimental AP (35). In the present study, the administration of CL induced HO-1 expression in the pancreas (Fig. 7). These results suggest that CL can inhibit cerulein-induced pancreatitis through the induction of $\mathrm{HO}-1$.

In conclusion, this study demonstrates that $\mathrm{CL}$ attenuates the severity of cerulein-induced AP and pancreatitis-associated lung injury through the inhibition of tissue injury and proinflammatory cytokine production and also inhibits acinar cell death and cytokine production. CL exerts potent antiinflammatory activities in AP and could be a beneficial agent in AP and its pulmonary complications.

\section{Acknowledgements}

This study was supported by the Korea Research Foundation Grant funded by the Korean Government (MOEHRD) (KRF355-2007-1-E00023).

\section{References}

1. Lund H, Tønnesen H, Tønnesen MH and Olsen O: Long-term recurrence and death rates after acute pancreatitis. Can J Gastroenterol 41: 234-238, 2006.

2. Rau B, Uhl W, Buchler MW and Beger HG: Surgical treatment of infected necrosis. World J Surg 21: 155-161, 1997.
3. Baron TH and Morgan DE: Acute necrotizing pancreatitis. N Engl J Med 340: 1412-1417, 1999.

4. Ho HS and Frey CF: Gastrointestinal and pancreatic complications associated with severe pancreatitis. Arch Surg 130: 817-822, 1995.

5. Beger HG, Rau B, Mayer J and Pralle U: Natural course of acute pancreatitis. World J Surg 21: 130-135, 1997.

6. Saluja AK and Steer MLP: Patho-physiology of pancreatitis. Role of cytokines and other mediators of inflammation. Digestion 60: 27-33, 1999 .

7. Steinberg W and Tenner S: Acute pancreatitis. N Engl J Med 330: 1198-1210, 1994.

8. Norman J: The role of cytokines in the pathogenesis of acute pancreatitis. Am J Surg 175: 76-83, 1998.

9. Lane JS, Todd KE, Gloor B, Chandler CF, Kau AW, Ashley SW, Reber HA and McFadden DW: Platelet activating factor antagonism reduces the systemic inflammatory response in a murine model of acute pancreatitis. J Surg Res 99: 365-370, 2001.

10. Hu Z, Wang Y, Luo G and He L: Estimation of measurement uncertainty of analytical results for the determination of three active components from Gardenia jasminoides Ellis. by HPLC. Zhong Yao Cai 28: 991-994, 2005.

11. Miquel J, Bernd A, Sempere JM, Diaz-Alperi J and Ramirez A: The curcuma antioxidants: pharmacological effects and prospects for future clinical use. Arch Gynecol Obstet 34: 37-46, 2002.

12. Joe B, Vijaykumar M and Lokesh BR: Biological properties of curcumin-cellular and molecular mechanisms of action. Crit Rev Food Sci Nutr 44: 97-111, 2004.

13. Jung WS, Chae YS, Kim DY, Seo SW, Park HJ, Bae GS, Kim TH, Oh HJ, Yun KJ, Park RK, Kim JS, Kim EC, Hwang SY, Park SJ and Song HJ: Gardenia jasminoides protects against ceruleininduced acute pancreatitis. World J Gastroenterol 14: 6188-6194, 2008.

14. Panozzo MP, Basso D, Fabris C, Faggian D, Meggiato T, Plebani M, Del Favero G, Fogar P, Scalon P and Ferrara C: Diagnostic utility of a new monoclonal antibody pancreatic isoamylase assay in chronic pancreatic diseases. J Clin Chem Clin Biochem 28: 485-488, 1990.

15. Panteghini M, Pagani F and Bonora R: Clinical and analytical evaluation of a continuous enzymatic method for measuring pancreatic lipase activity. Clin Chem 39: 304-308, 1993.

16. Ethridge RT, Chung DH, Slogoff M, Ehlers RA, Hellmich MR, Rajaraman S, Saito H, Uchida T and Evers BM: Cyclooxygenase-2 gene disruption attenuates the severity of acute pancreatitis and pancreatitis-associated lung injury. Gastroenterol 123: 1311-1322, 2002.

17. Ammon HP and Wahl MA: Pharmacology of Curcuma longa. Planta Med 57: 1-7, 1991.

18. Gukovsky I, Reyes CN, Vaquero EC, Gukovskaya AS and Pandol SJ: Curcumin ameliorates ethanol and nonethanol experimental pancreatitis. Am J Physiol Gastrointest Liver Physiol 284: G85-G95, 2003.

19. Rushworth SA, Ogborne RM, Charalambos CA and O'Connell MA: Role of protein kinase C delta in curcumininduced antioxidant response element-mediated gene expression in human monocytes. Biochem Biophys Res Commun 341: 1007-1016, 2006.

20. Lee TS and Chau LY: Heme oxygenase-1 mediates the antiinflammatory effect of interleukin-10 in mice. Nat Med 8: 240-246, 2002.

21. Hegazi RA, Rao KN, Mayle A, Sepulveda AR, Otterbein LE and Plevy SE: Carbon monoxide ameliorates chronic murine colitis through a heme oxygenase 1-dependent pathway. J Exp Med 202: 1703-1713, 2005.

22. Taille C, El-Benna J, Lanone S, Dang MC, Ogier-Denis E, Aubier $M$ and Boczkowski J: Induction of heme oxygenase-1 inhibits $\mathrm{NAD}(\mathrm{P}) \mathrm{H}$ oxidase activity by down-regulating cytochrome b558 expression via the reduction of heme availability. J Biol Chem 279: 28681-28688, 2004.

23. Dixit VP, Jain P and Joshi SC: Hypolipidaemic effects of Curcuma longa $\mathrm{L}$ and Nardostachys jatamansi DC in tritoninduced hyperlipidaemic rats. Indian J Physiol Pharmacol 32: 299-304, 1988.

24. Luper S: A review of plants used in the treatment of liver disease: part two. Altern Med Rev 4: 178-188, 1999.

25. Maheshwari RK, Singh AK, Gaddipati J and Srimal RC: Multiple biological activities of curcumin: a short review. Life Sci 78: 2081-2087, 2006. 
26. Seo SW, Jung WS, Lee SE, Choi CM, Shin BC, Kim EK, Kwon KB, Hong SH, Yun KJ, Park RK, Shin MK, Song HJ and Park SJ: Effects of bee venom on cholecystokinin octapeptideinduced acute pancreatitis in rats. Pancreas 36: e22-e29, 2008.

27. Sun J and Bhatia M: Blockade of neurokinin-1 receptor attenuates $\mathrm{CC}$ and $\mathrm{CXC}$ chemokine production in experimental acute pancreatitis and associated lung injury. Am J Physiol Gastrointest Liver Physiol 292: 143-153, 2007.

28. Exley AR, Leese T, Holliday MP, Swann RA and Cohen J: Endotoxaemia and serum tumour necrosis factor as prognostic markers in severe acute pancreatitis. Gut 33: 1126-1128, 1999.

29. Gross V, Leser HG, Heinisch A and Schölmerich J. Inflammatory mediators and cytokines - new aspects of the patho-physiology and assessment of severity of acute pancreatitis? Hepatogastroenterology 40: 522-530, 1993.

30. Heath DI, Cruickshank A, Gudgeon M, Jehanli A, Shenkin A and Imrie CW: Role of interleukin-6 in mediating the acute phase protein response and potential as an early means of severity assessment in acute pancreatitis. Gut 34: 41-45, 1993.
31. Dinarello CA, Gelfand JA and Wolff SM: Anti-cytokine strategies in the treatment of systemic inflammatory response syndrome. JAMA 269: 1829-1835, 1993.

32. Pooran N, Indaram A, Singh P and Bank S: Cytokines (IL-6, IL-8, TNF): early and reliable predictors of severe acute pancreatitis. J Clin Gastroenterol 37: 263-266, 2003.

33. Maines MD: The heme oxygenase system: a regulator second messenger gases. Annu Rev Pharmacol Toxicol 37: 517-554, 1997.

34. Otterbein LE, Soares MP, Yamashita K and Bach FH: Heme oxygenase-1: unleashing the protective properties of heme. Trends Immunol 24: 449-455, 2003.

35. Nakamichi I, Habtezion A, Zhong B, Contag CH, Butcher EC and Omary MB: Hemin-activated macrophages home to the pancreas and protect from acute pancreatitis via heme oxygenase-1 induction. J Clin Invest 115: 3007-3014, 2005. 